\title{
Social Network Analysis
}

\author{
Sukharev O. S., Kurmanov N.V." \\ The Institute of Economy of Russian Academy of Sciences \\ *Corresponding Author: nik@kurmanov.com
}

Copyright @ 2014 Horizon Research Publishing All rights reserved.

\begin{abstract}
The article presents the author's model of marketing analysis of social network, which was tested on the firm Internet-community. Key indicators of commercial Internet-community efficiency are developed. They are: the coefficient of commercial activity, the interaction coefficient of the Internet-community participants and target group coverage.
\end{abstract}

Keywords E-Marketing, Social Network, Viral Marketing, Marketing Assessment, Target Group

\section{Social Network and the Problems of Its Marketing Assessment}

Such marketing area as promotion of commercial communities in the Internet is being actively developed today. Thousands of such communities have been already created. The urgency of this area is proved by the research of Russian Public Opinion Research Centre (RPORC) on social networks popularity where the conclusion is made, that every second Internet-user uses social networks. The most popular communities according to daily attendance in percentage are: vk.com(31\%) andOdnoklassniki.ru(21\%). Other services are not so popular, the attendance of them makes about 18 percent. They are:Twitter.com, Blog.ru, Facebook.com, MySpace.com, Liveinternet.ru, Livejournal.ru, Mamba.ru. It is possible to assume, that advertisers' involvement has the same percentage respectively. We formulated the problem of social media use for commercial purposes in the following way: there is no opportunity and methodological basis of real utility assessment of commercial Internet-communities.

It is necessary to single out a separate area. It is marketing analysis of Internet-community efficiency. Not only is the quantity of community participants of primary value here, but also their activity level. Thus, it is necessary to develop a complex of indicators, which will reflect marketing value of Internet-community, and to show the activity level of social network users objectively.

Marketing efficiency of Internet-community can be considered in two directions: Internet-community content and communication. Content efficiency is characterized by the relevance and frequency of publications. Content relevance assumes conformity to the community subject matter, commercial orientation and aspiration to raise users' motivation to fulfill the target action, i.e. to purchase. Frequency of publications allows influencing the target group constantly. This has an influence on regularity of users' involvement into the interaction with the commercial content.

Communication with users in the Internet-community is the following actions:

1) production or services distribution;

2) after-sale service (or consulting);

3) consumer's preference judgment;

4) analysis of strong and weak sides of production or services (by receiving information from the users of Internet-community). This point is especially important, since it allows receiving consumer's estimation of the company's commercial products.

Thus, we form the following hypothesis: true value and utility of a social network (Internet-community) depends on the totality of users' qualitative actions during a certain period of time. Qualitative actions presuppose consumption of Internet-community content and communication with both representatives of the industrial enterprise, and with other participants of the given Internet-community.

Now Metcalf's law is used to solve this problem. According to this law, network utility is approximately equal to a half square of the network users. But since the user cannot connect to himself, the formula [6], [7] is:

$$
E=\frac{n^{2}-n}{2}
$$

where

E - social network utility;

$\mathrm{n}$ - number of a social network.

Let's check the given formula in operation. We will estimate the community utility numbering 1000 users. The given quantity of participants is spread in the commercial communities. After calculations we've got, that the network utility is approximately equal to 499500 users. The result can be doubted, because such audience is comparable with the population of a large city.

If we consider methodological basis of practitioners, namely the experts who are actively busy with promotion of 
commercial Internet-communities in popular social media, it is worth paying attention to marketing workings out of the company LLC "France Group" [1]. It is necessary to study the articles [1], discussing the users' involvement in marketing estimation of Internet-community as the most important factor. On the one hand, this variant adds objective information, since the company "France Group" does not perceive the quantitative index in the form of community participants number as the key parametre of a social network efficiency. But it is necessary to notice, that such approach does not allow estimating efficiency of the marketing tool fully. This technique is not connected with getting a commercial result, and the analysis process covers only the stages of content consumption and communications of various character.

Thus, we come to the conclusion, that methodical basis for marketing assessment of social networks is not worked out. It is necessary to develop the model of complex analysis of commercial Internet-communities, with the help of which it will be possible to define the real audience coverage, the level of activity and the involving of users into interaction. And more than that it will be possible to define commercial effectiveness of a social network objectively.

\section{Model of the Marketing Analysis of a Social Network}

The author's model is developed for commercial Internet-communities, but it is possible to apply it both for social network as a whole, and for separate user's profiles. This model includes quantitative, qualitative and commercial indicators which allow versatile estimation of Internet-community, and making conclusions. For example, to estimate quality of the target group and commercial information, to carry out the analysis of the level of Internet-community commercial utility. Let's consider the analysis scheme of the basic efficiency indicators of a social network.

The main point of Figure 1 is that a social network, as well as the commercial Internet-community, assumes marketing importance only at a certain coverage level of the target group in combination with the sufficient communications level of the participants of this community. As a result, social network commercial activity is formed. The indicators of audience coverage, interaction of the users and commercial activity combined together make up the objective utility of commercial Internet-community.

Characteristic of author's model indicators:

1) Commercial activity. It directly reflects the commercial result and shows the network efficiency, as a market channel of the enterprise's production.

2) Interaction factor of Internet-community participants. It shows, how much the users are involved in the interaction with this community content.

3) Audience coverage. It contains information about the real number of users on whom this Internet-community has informational impact.

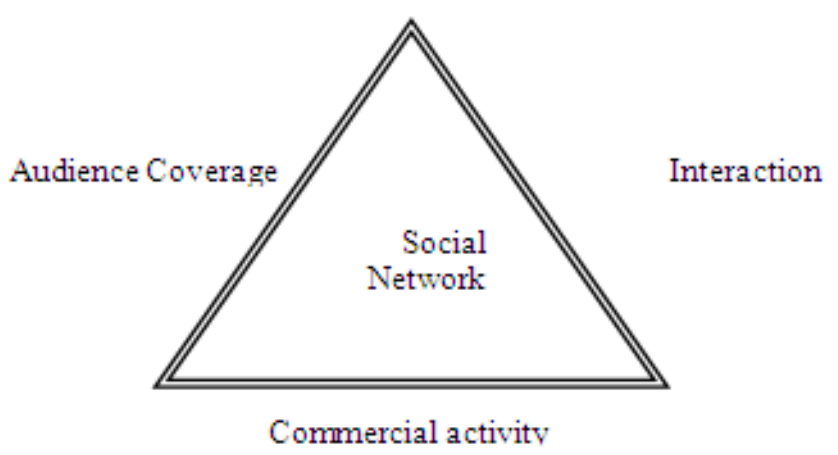

Figure 1. The Scheme of Efficiency Directions of a Social Network.(Developed by the author)

Thus, we suggest the following system of indicators:

$$
E_{\text {network }}=\left\{\begin{array}{c}
\mathrm{K}_{\text {commercial activity. }} \\
\mathrm{K}_{\text {interaction. }} \\
\mathrm{Q}_{\text {audience. }}
\end{array}\right.
$$

where

$E_{\text {network }}$ - marketing value of a social network;

$\mathrm{K}_{\text {commercial activity. }}$

-commercial activity factor of Internet-community audience;

$\mathrm{K}_{\text {interaction. }}$

-interaction factor of Internet-community participants;

$\mathrm{Q}_{\text {audience. }}$-target audience coverage by Internet-community.

Such approach allows fully estimating a concrete Internet-community as a marketing instrument which can carry out the promotion functions, production distribution and estimate buyers' qualitative preferences.

Internet-community participants' activity can be divided into 2 types: commercial activity and interaction. Commercial activity is connected with the actions which provide economic gain to the industrial enterprise. Interaction is manifested in unilateral and bilateral communication and in the actions connected with the use of Internet-community features and with getting general or organizational information. 


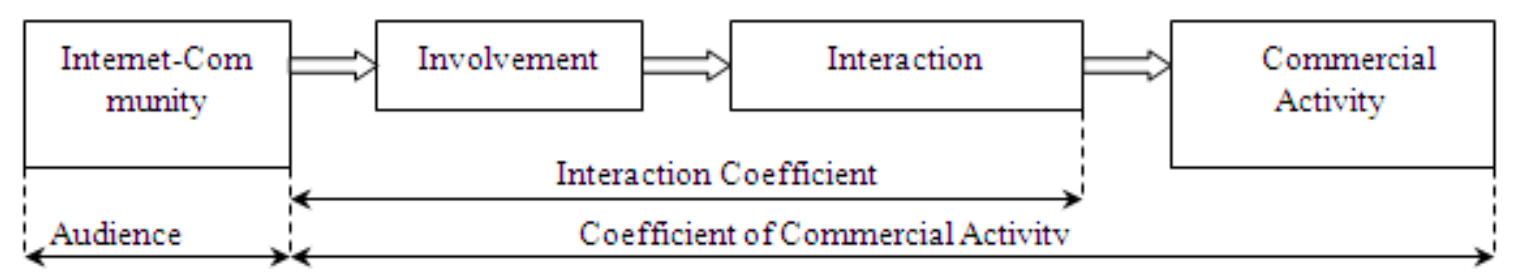

Figure 2. Highlighting of Marketing Indicators in the Scheme of Commercial Action (Developed by the author).

Figure 2 represents the scheme of commercial action in the Internet-community, that is, the ratio of concrete stages and marketing estimation indicators of social network. The task of this scheme is to give an idea, that the commercial activity coefficient and audience coverage are at one level of one logic chain, and the interaction coefficient is a key stage of users' commercial actions.

\section{Commercial Activity Coefficient}

This coefficient exactly reflects the commercial results of Internet-community, since it depends on the total amount of community users and the number of users who have made a commercial action. Thus, we develop the following formula:

$$
K_{\text {commercialactivity. }}=\frac{q_{2}}{q_{1}}
$$

where

$$
0 \leq K_{\text {com.activity. }} \leq 1
$$

$\mathrm{K}_{\text {commercial activity. }}$ - users' commercial activity coefficient; $q_{1}$-total amount of Internet-community participants; $q_{2}$-number of the Internet-community participants, who has made the target (commercial) action (calculated according to the information about concrete users in the accounting program of clients interrelations).

Change of the commercial activity coefficient will indicate to the positive or negative development dynamics of enterprise Internet-community accordingly.

\section{Audience Interaction Coefficient}

It is generally known that unique identification number is given to all of Internet-community participants at registration. Hence, if we distinguish all the possible activity of the users according to the stages, it is possible to generate activity rating of concrete Internet-community participants. Let's distinguish the users' activity according to the stages:

1) Passive state.Users are Internet-community participants, but they do not demonstrate any activity, and, probably, fully ignore the received information;

2) Profile browsing. Users' activity is limited only to browsing the main page of enterprise's profile;

3) Content consumption. Users browse the content, but do not communicate;
4) Interaction with the content. Users browse the content and communicate unilaterally (comments and notes, when interests coincide);

5) Communications. Communication actions with the representatives of the industrial enterprise;

6) Commercial action. Purchase of enterprise's production by the Internet-community participant.

For activity estimation of the Internet-community audience, we develop the respective table 1 which is divided according to the users' activity stages. The stages are descending from 5 to 0 . Then, all the actions of each user are studied and correlated with the activity stages generated earlier. As a result, the activity stage, which corresponds to the maximum activity type, is appointed to the user. If the user consumed the content, communicated with enterprise's representatives and purchased the production, the $5^{\text {th }}$ activitystage is appointed to him.

Table 1. Activity Rating of Internet-community audience.(Developed by the author.)

\begin{tabular}{|c|c|l|}
\hline $\begin{array}{c}\text { Activity } \\
\text { Stages }\end{array}$ & Audience Share & $\begin{array}{l}\text { The Description of the Activity } \\
\text { Stage }\end{array}$ \\
\hline 5 & $\mathrm{r}_{5}$ & - Commercial action \\
\hline 4 & $\mathrm{r}_{4}$ & - Communication; \\
\hline 3 & $\mathrm{r}_{3}$ & - Interaction with the content; \\
\hline 2 & $\mathrm{r}_{2}$ & - Content consumption; \\
\hline 1 & $\mathrm{r}_{1}$ & - Profile browsing; \\
\hline 0 & $\mathrm{r}_{0}$ & - Passive condition. \\
\hline
\end{tabular}

For visual representation of the values, a type diagram is developed, which reflects a percentage share change for each activity stage of Internet-community audience with the course of time.

Thus, the marketing department of the industrial enterprise has the opportunity to estimate the efficiency of production and a brand promotion in social media. The Internet-community should be active, i.e. it should be constant replenished with communication content by the participants of this community. If the audience activity is minimum, the following conclusions can be made:

1) the target group is chosen incorrectly;

2) the profile (questionnaire) of the enterprise is presented incorrectly;

3) the level of thematic content is not sufficient;

4) enterprise's production is positioned inefficiently;

5) absence of communications with enterprise's 
representatives;

6) users' communication is ignored;

7) enterprise's production is not competitive according to certain parametres (for example, the price);

8) absence of flexible approach to payment (for example, there is no opportunity to accept payment after production delivery or to pay through the Internet);

9) absence of delivery (including C.O.D. (cash on delivery);

It is necessary to notice, that conclusions 7,8,9 refer to the general problems of the enterprise (marketing services, in particular), and it is impossible to solve them by Internet marketing. Hence, the percentage shares sum of stages $4\left(r_{4}\right)$ and $5\left(\mathrm{r}_{5}\right)$ will be characterised as the general activity indicator of the Internet-community audience. We expressed it mathematically:

$$
\mathrm{K}_{\text {interaction. }}=r_{4}+r_{5}
$$

where

$\mathrm{K}_{\text {interaction - Interaction ratio of Internet-community }}$ participants;

$r_{4}$ - Audience amount on the 4th activity stage of Internet-community;

$r_{5}$ - Audience amount on the 5th activity stage of Internet-community.

The total score of audience activity represents the efficiency of Internet-community which shows objectively how effectively and successfully the users are involved in communication with enterprise's representatives.

\section{Audience Coverage}

To evaluate the coverage of the social network audience, it is necessary to estimate users' actions both inside, and outside the Internet-community. We suggest the following formula for coverage evaluation of the social network audience:

$$
Q_{\text {audience. }}=q_{1}-q_{0}+N_{\text {outside }}
$$

where

$\mathrm{Q}_{\text {audience }}$ - real audience coverage of the Internet-community; $\mathrm{q}_{1}$ - total number of Internet-community participants;

$q_{0}$ - number of Internet-community participants who are not active, are blocked by social network administration or are spams-robots;

$\mathrm{N}_{\text {outside }}$ - number of the users, who are not a part of the Internet-communities, but who experienced information influence.

For exact calculation of $\mathrm{N}_{\text {outside. }}$, we developed 3 types of information influence on Internet-community users:

1) Broadcast. General demonstration of community content or information about the community to other users with implicit commercial action (for example, citing of the content by the Internet-community participant in his own news line);

2) Reference. Personal content demonstration or other information by the Internet-community participant with an implicit commercial effect;

3) Involvement. Personal reference of Internet-community content to undertake a commercial or other target action.

But the way of information distribution by the users outside the Internet-community is difficult to describe mathematically since the information transfer is characterized by some randomness. It is necessary to continue the description of the method within the limits of virus marketing model and to ignore the influence of the factor $\mathrm{N}_{\text {outside }}$.. Thus, we suggest calculating $\mathrm{Q}_{\text {audience }}$. on the formula:

$$
Q_{\text {audience. }}=q_{1}-q_{0}
$$

As a result, the real coverage of the Internet-community audience is calculated as the total number of the given community participants except for the users who do not show any Internet activity or are spam-robots.

\section{Testing of the Research Results}

Testing of the author's model of social network marketing analysis was carried out on the example of the company Emercom Ltd which works in the sphere of intellectual services, and its buyers are legal entities from different regions of the Russian Federation.

Let's consider the activity period of Internet-community Emercom Ltd from March, 15th till April, 15th, 2012. The data are presented in Table 2.

Table 2. Information about the Activity of Internet-community Emercom Ltd

\begin{tabular}{|c|c|c|c|}
\hline Control date & $\begin{array}{c}\text { Participants } \\
\text { Number }\end{array}$ & $\begin{array}{c}\text { Clients } \\
\text { Number }\end{array}$ & $\begin{array}{c}\text { Sales } \\
\text { Volume, rbl. }\end{array}$ \\
\hline 16.03 .2012 & 133 & 1 & 253000 \\
\hline 23.03 .2012 & 142 & 2 & 570000 \\
\hline 30.03 .2012 & 149 & 2 & 430000 \\
\hline 04.04 .2012 & 140 & 1 & 310000 \\
\hline 11.04 .2012 & 158 & 3 & 846000 \\
\hline Total: & - & 9 & 2409000 \\
\hline
\end{tabular}

Thus, using the Internet-community in marketing of Emercom Ltd, 9 clients were involved who ordered services to the sum of $2409000 \mathrm{rbl}$. Let's perform full marketing analysis of the social network of Emercom Ltd according to the author's technique.

Let's calculate commercial activity coefficient according to the control stages and on the total score of Internet-community marketing activity.

As a result, we can see the dependence between 
Internet-community participants increase and increase of commercial activity coefficient. Figure 3 presents the results of Table 3 graphically.

Table 3. Calculation of Users' Commercial Activity Coefficient of Emercom Ltd Internet-community

\begin{tabular}{|c|c|c|c|}
\hline Control date & $\begin{array}{c}\text { Participants } \\
\text { Number }\end{array}$ & $\begin{array}{c}\text { Clients } \\
\text { Number }\end{array}$ & $\begin{array}{c}\mathrm{K}_{\text {commercial }} \\
\text { activity. }\end{array}$ \\
\hline 16.03 .2012 & 133 & 1 & 1 \\
\hline 23.03 .2012 & 142 & 2 & 2 \\
\hline 30.03 .2012 & 149 & 2 & 2 \\
\hline 04.04 .2012 & 140 & 1 & 1 \\
\hline 11.04 .2012 & 158 & 3 & 3 \\
\hline
\end{tabular}

Thus, it is possible to make a conclusion, that there is no direct relation of commercial activity coefficient on the number of Internet-community participants. Let's calculate the interaction coefficient of Internet-community users on the control stages. The data are presented in Table 4.

Let's present the calculation results of interaction coefficient of Internet-community Emercom Ltd audience graphically.

Thus, from Figure 4 it is possible to make a conclusion, that the number of Internet-community users directly influences the interaction coefficient of community users, communication level in the community and users' activity degree in the interaction with the commercial content. But there is one more dependence. With the number increase of community users, the share of the audience, which only browses the profile of the commercial organization, decreases. But with the reduction of the participants number, this indicator increases, hence, the content of Emer com Ltd Internet-community became irrelevant. This factor influences the marketing state of the community negatively. Potential buyers were not only lost, but communication and commercial activity lowered.

Table 4. Calculation of Interaction Coefficient of Internet-community Emercom Ltd Audience

\begin{tabular}{|c|c|c|c|c|c|c|c|}
\hline Stages & $\mathrm{r}_{0}$ & $\mathrm{r}_{1}$ & $\mathrm{r}_{2}$ & $\mathrm{r}_{3}$ & $\mathrm{r}_{4}$ & $\mathrm{r}_{5}$ & $\begin{array}{c}\text { Audience } \\
\text { Interaction } \\
\text { Ratio, \% }\end{array}$ \\
\hline $\begin{array}{c}\text { Control } \\
\text { Stage 1 }\end{array}$ & 22 & 67 & 28 & 10 & 5 & 1 & 4,5 \\
\hline $\begin{array}{c}\text { Control } \\
\text { Stage 2 }\end{array}$ & 28 & 52 & 37 & 14 & 9 & 2 & 7,7 \\
\hline $\begin{array}{c}\text { Control } \\
\text { Stage 3 }\end{array}$ & 34 & 37 & 46 & 19 & 11 & 2 & 8,7 \\
\hline $\begin{array}{c}\text { Control } \\
\text { Stage 4 }\end{array}$ & 31 & 55 & 35 & 12 & 6 & 1 & 5 \\
\hline $\begin{array}{c}\text { Control } \\
\text { Stage 5 }\end{array}$ & 39 & 30 & 49 & 23 & 14 & 3 & 10,8 \\
\hline
\end{tabular}

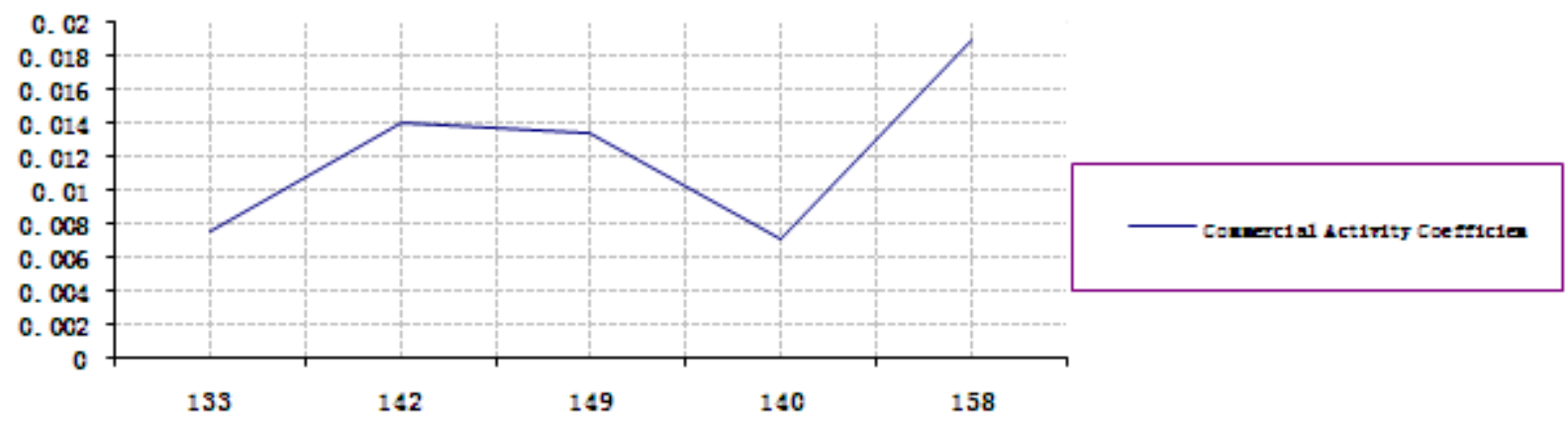

Figure 3. Dependence of Commercial Activity Coefficient on the Number of Emercom Ltd Internet-community Participants

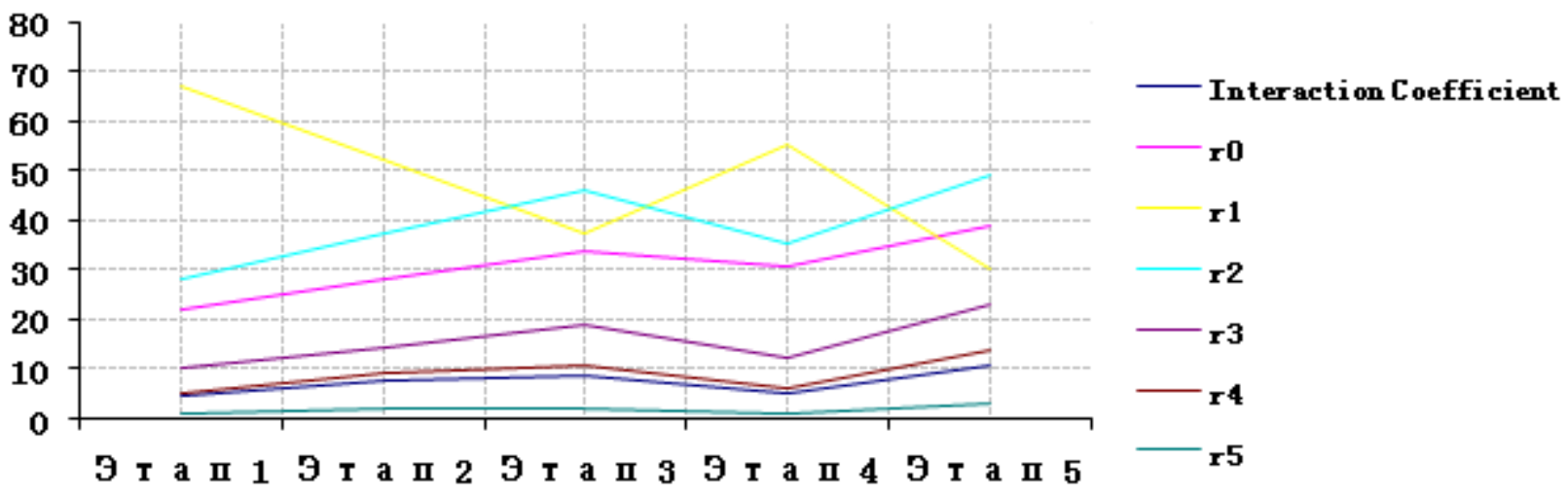

Figure 4. Calculation Results of Audience Interaction Coefficient 
Let's determine the target audience coverage by Emercom Ltd Internet-community. The data are presented in Table 5.

Table 5. Target Audience Coverage by Emercom Ltd Internet-community

\begin{tabular}{|c|c|c|c|}
\hline Stages & $\mathrm{q}_{1}$ & $\mathrm{q}_{0}$ & Qaudience. \\
\hline Control Stage 1 & 133 & 5 & 128 \\
\hline Control Stage 2 & 142 & 7 & 135 \\
\hline Control Stage 3 & 149 & 9 & 140 \\
\hline Control Stage 4 & 140 & 6 & 134 \\
\hline Control Stage 5 & 158 & 11 & 147 \\
\hline
\end{tabular}

Thus, on the basis of calculation results of Table 5, the minimum value is at the first stage, the audience coverage is 128 users. At the last stage the audience coverage by the Internet-community is the largest and constitutes 147 users. It is $15 \%$ more than the result at the first stage.

\section{Conclusions}

As a result of research, we developed our own model of social network marketing analysis and it was approved on the example of Emercom Ltd Internet-community. With the help of the author's model, it is possible to carry out complex analysis of a social network. Such analysis uses 3 factors:

1) users' commercial activity coefficient;

2) users' interaction coefficient;

3) audience coverage by the Internet-community.

Research scientific hypothesis was generated: true value and utility of a social network (Internet-community) depends on the set of users' qualitative actions during a certain period of time. Qualitative actions presuppose consumption of Internet-community content and communication with both representatives of the industrial enterprise, and other participants of the given Internet-community.

As a result of the marketing analysis of Emercom Ltd Internet-community the following regularities were revealed.

1) There is no direct dependence of commercial activity coefficient on the number of Internet-community participants.

2) Increase of Internet-community users' number directly influences the users' interaction coefficient increase, communication level of community, users' activity degree in the interaction with the commercial content. But the reduction of participants number indicates to worsening of Internet-community marketing component. And it directly influences the decrease of commercial effectiveness of a social network.

In the course of the development of the marketing analysis model of social media efficiency the author formulated the following scientific theory: real utility of commercial Internet-community depends on audience coverage, interaction of content users and the results of commercial activity of the given Internet-community.

The author's model can be used for the analysis of both commercial and public communities (The difference will be in the participants' target actions.). We suggest implementing the given model in the typical functional of social network, automating the calculations process and giving proprietors of Internet communities the possibility to carry out the marketing analysis and to reveal the problems in order to maximize commercial results operatively.

\section{REFERENCES}

[1] Arabie, P. and Wind, Y., 1994. Marketing and Social Networks. In Advances in Social Network Analysis, S.Wasserman and Galaskiewicz, J. (Eds.), Sage Publications, Thousand Oaks

[2] Achrol, R.S., 1997. Changes in the theory of interorganizational relations in marketing: Toward a network paradigm. Journal of the Academy of Marketing Science 25 (1), 56-71.

[3] Goldenberg, J., Libai, B., and Muller, E., 2001. Talk of the network a complex systems look at the underlying process of word-of-mouth. Marketing Letters 12 (3), 211-223.

[4] Iacobucci, D., and Ostrom, A., 1996. Commercial and interpersonal relationships: Using the structure of interpersonal relationships to understand individual-to individual, individual-to-firm, and firm-to-firm relationships in commerce. International Journal of Research in Marketing $13,53-72$.

[5] Krackhardt, D., 1987. Cognitive social structures. SocialNetworks 9, 109-134.

[6] Melancton, R 2001. Zen and the Art of Selling, Technology Review, May/June 1992

[7] Melancton, R 2001. Packet Communication, MIT Project MAC Technical Report MAC TR-114, December, 1993

[8] Moorman, C. and Matulich, E., 1993. A model of consumers' preventive health behaviors: The role of health motivation and health ability. Journal of Consumer Research 20, 208-228.

[9] Reingen, P.H., Foster, B.L., Brown, J.J., and Seidman, S.B., 1984. Brand congruence in interpersonal relations: A social network analysis. Journal of Consumer Research 11, 771-783.

[10] Reingen, P.H. and Kernan, J.B., 1986. Analysis of referral networks in marketing: Methods and illustration. Journal of Marketing Research 23, 370-378.

[11] Scott, J., 1991. Social Network Analysis: A Handbook. Sage Publications, Newbury Park.

[12] Wilkinson, I.F., 2001. A history of network and channels thinking in marketing in the 20th Century. Australasian Marketing Journal 9 (2), 23-52http://www.fastcompany.com 